\title{
An Ethnographic Focus on Family Dynamics in Ghana, West Africa versus the United States
}

\author{
Jalynn Malon Stubbs ${ }^{1}$ and Medha Talpade ${ }^{1}$
}

${ }^{1}$ Clark Atlanta University, Atlanta, GA,USA

DOI: 10.47611/jsr.v9i1.1047

\section{$\underline{\text { ABSTRACT }}$}

The purpose of this study to explore and describe the family dynamics in Ghana, West Africa in comparison to those of African Americans in the United States of America. Analyzing these culture sharing patterns is especially important in the context of the historically black institution of higher learning, where African and American cultures intersect. Both groups, Africans in Africa and African-Americans in the U.S., will benefit from this research because this will bridge gaps in knowledge, making us a citizen of the world. I was able to travel to Ghana and immerse myself into their culture and for that short period of time, I was able to observe the differences in family dynamics in America versus those in Ghana. My research explores family dynamics in three sectors: Daily life, education, marriage/childbearing. Many components make these three overarching sectors. Both Ghana and America are countries going through changes with a diverse population that provides different perspectives and opportunities for the exchange of new ideas that can stimulate innovation and creativity (VanAlstine, Cox, \& Roden, 2015). Research has been conducted to investigate the educational system in both America and Ghana and the different levels in which one can obtain a degree/certificate. Studies also explore the extent to which families in both Ghana and America value education. Marriage practices also differ in Ghana versus the United States and have changed many times over centuries. This study is important in that it explores these differences based on the lived experiences of the participants who are a part of each culture. In order to collect data, three focus groups were conducted among college students in both Ghana and the United States. Students who attended The University of Ghana, The University of Cape Coast, and students of the Atlanta University Center shared their lived experiences and their family dynamics. There were a total of 13 interview questions in order to explore daily life, education, roles/hierarchy, occupation, and marriage. All questions asked were open-ended, allowing the participants to discuss their experiences in detail. For example, "Describe the roles of men and women in your family" is a question that received extensive responses due to the fact that is was more subjective than objective. Atlas Ti revealed the following themes that arose from the analysis-meals, leisure activities, the value of education, attitudes toward premarital childbearing, and family roles among others. Validation strategies used are rich thick descriptions, reflexivity, and member checking. Understanding the daily lives and contexts of individuals in Ghana and in the U.S. has not been conducted systematically to date, and such an exploration is expected to help build a bridge of understanding and respect between the related cultures in addition to using best practices that will benefit the cultures mutually. 


\section{Introduction}

Research has been conducted to investigate the educational system in both America and Ghana and the different levels in which one can obtain a degree/certificate. Studies also explore the extent to which families in both Ghana and America value education. Marriage practices also differ in Ghana versus the United States and have changed many times over centuries. This study is important in that it explores these differences based on the lived experiences of the participants who are a part of each culture. In order to collect data, three focus groups were conducted among college students in both Ghana and the United States. Students who attended The University of Ghana, The University of Cape Coast, and students of the Atlanta University Center shared their lived experiences and their family dynamics. There were a total of 13 interview questions in order to explore daily life, education, roles/hierarchy, occupation, and marriage. All questions asked were open-ended, allowing the participants to discuss their experiences in detail. For example, "Describe the roles of men and women in your family" is a question that received extensive responses due to the fact that is was more subjective than objective. Atlas Ti revealed the following themes that arose from the analysis - meals, leisure activities, the value of education, attitudes toward premarital childbearing, and family roles among others. Validation strategies used are rich thick descriptions, reflexivity, and member checking. Understanding the daily lives and contexts of individuals in Ghana and in the U.S. has not been conducted systematically to date, and such an exploration is expected to help build a bridge of understanding and respect between the related cultures in addition to using best practices that will benefit the cultures mutually.

We do not currently know about the in-depth family dynamics in the American and African cultures. Analyzing these patterns will assist us in better understanding in what ways they are related or contrast. This is especially important in the context of the historically black institution of higher learning, where African and American cultures intersect. Both groups, Africans in Africa and African-Americans in the U.S., will benefit from this research because this will bridge gaps in knowledge, making us a citizen of the world. My research explores family dynamics in five sectors: Daily life, education, roles/hierarchy, occupation, and marriage/childbearing. Such exploration has not been conducted yet.

\section{Literature Review}

There has been some research on the daily lives of people in Ghana as well as the U.S. (Adu-Agyem \& Osei-Poky, 2012; Hammond, 2016; Boateng \& Maier, 2019; Nsowah-Nuamah, Teal, 2012). For example, Adu-Agyem and OseiPoky (2012) stated, "in Ghana, inadequate standardized human and material resources, poor management and supervision, lack of funding and poor conditions of service for employees of the educational system culminate in low productivity." In the United States, there are gaps in the educational system as well as achievement for Black students. Educational outcomes for minority children are much more a function of their unequal access to key educational resources, including skilled teachers and quality curriculum, than they are a function of the race (Hammond, 2016). Minority students are given less resources and are given teachers that may or may not be experts in the area they are teaching. Traditional social values, such as respect for elders and the veneration of dead ancestors, are generally more evident among the rural than the urban population (Boateng \& Maier, 2019). Rural areas lean on more on basic values 
set in place by their ancestors. Their adherence to these traditions is unwavering. When it comes to hierarchy in America. there is not a defined caste system, and the households are mostly lead by mothers. In the Black community, $73 \%$ of households are single-mother lead. In the country of Ghana, earnings increase rapidly with education and the more advanced the degree, the higher the income for that family or individual (Nsowah-Nuamah, Teal, 2012). This is also apparent in the United States, where, the more advanced the degree level, the higher the income of the household. Understanding the daily lives and contexts of individuals in Ghana and in the U.S. has not been conducted systematically to date, and such an exploration will help build a bridge of understanding and respect between the related cultures in addition to using best practices that will benefit the cultures mutually.

\section{Daily Life}

\section{Daily Life in Ghana}

There are contrasts in urban and rural areas when it comes to dressing and dietary patterns, with the urban occupants being particularly more Westernized and sophisticated (Boateng, Fage, Davies, \& Maier, 2019).

\section{Meals}

Reflecting on the country's agricultural wealth and varied historical connections, most of their meals include fufu and other starchy foods such as ass cassava, yams, or plantains. Kenke is also an ingredient used in making these dishes. Groundnut (peanut) soup, palm nut soup, fish, and snails are also dishes indigenous to the Ghanaian culture (Fage et. al., 2019).

\section{Leisure}

After Ghana became independent in 1957, President Kwame Nkrumah encouraged the development of sports in order to generate recognition and representation internationally (Fage et. al., 2019). Backed by the support of the government in the 1960s, there were giant strides in the development of athletics, especially boxing, track \& field, and futbol (soccer).

\section{Gender roles}

The gender gaps that exist in education, income, poverty, access to health and wealth, inheritance, and household decision-making has been reported widely in Ghana and in Africa (Bosak, Eagly, Diekman, \& Sczesny, 2017). These gaps most negatively impact Ghanaian women. Both boys and girls learn to distinguish male and female roles by watching the elders around them (Ampofo, 2001). These elders are close to them, some parents/grandparents. Ampofo (2001) goes on to say that in Ghanaian societies, female children are at the bottom of the totem pole. They are raised to assume domestic/marital roles (cooking, cleaning, catering to the needs of their children/husband), while young boys are raised to take on paternal responsibilities which include being the head of the household and having professional jobs. Men make the majority of decisions including those that have to do with the reproduction of their wives. 


\section{Daily Life in the USA}

America is a highly diverse country. A diverse population provides different perspectives and opportunities for the exchange of new ideas that can stimulate innovation and creativity (VanAlstine, Cox, \& Roden, 2015).

\section{Meals}

In American culture, food that is consumed on a daily basis originates from various ethnic backgrounds. Most American food comes from animals (beef, turkey, fish, chicken, etc.) Like Ghanainan culture, some foods are grown in gardens or on farms (vegetables, grains, etc.) At the turn of the 20th century, the majority of Americans ate most of their meals at home, prepared from foods both grown at home and purchased from local stores. Now, there are many fast-food chains that make meals more accessible and also appear to be cheaper than local grocery stores.

\section{Gender roles}

Women in the United States have made significant strides toward closing the gaps that have kept them from achieving equality with men (Horowitz, Parker, \& Stepler, 2017). This is seen in educational achievement and also in the workplace. In Western cultures, women are perceived to be the more nurturing gender therefore, women were expected to in nurturing roles. These roles included tending to her family in the home full-time without having to go to work outside of the home. Traditionally, many Western societies have believed that women are more nurturing than men. Men, on the other hand, are presumed by traditional views of gender roles to be leaders, which is similar to the Ghanaian culture (Blackstone, 2003).

\section{Education}

\section{Education in Ghana}

The present education in Ghana runs through Basic school education up to Tertiary education. The Basic education system covers a period of nine years: six of those years are allocated by Primary school education, and the other three years consists of Junior High School education. These years are followed by four years of Senior High School education, or Technical and Vocational Education (Adu--Agyem \& Osei-Poku, 2012). Tertiary education in Ghana is education at the University, Polytechnical, or any other Post Secondary Degree level.

\section{Educational values}

Ghanaian training is focused on giving an all-encompassing and quality way of education by creating well-balanced individuals with the essential learning, abilities, qualities, and aptitudes with the end goal of self-acknowledgment and for the financial advancement and political transformation of the nation. According to Adu--Agyem \& Osei-Poku (2012), in order to accomplish this, the individual is taught ought to be mentally, intellectually, psychologically developed so as to contribute towards national improvement and adjust to changes and different developments within the nation and beyond positively. 


\section{Education in The United States}

Similar to Ghanaian culture, education in the United States starts with primary school and ends with postgraduatelevel degrees. A student in the U.S. goes through pre-kindergarten, gets promoted to elementary, middle school (junior high), and moves up to the high school level. After high school, a student attends college or a vocational/trade school and upon graduation, they have the option to attend a postgraduate school to receive a more advanced degree (Masters, Ph.D., etc).

\section{Educational values}

Citizens recognize the value of education, particularly during times of economic turmoil, which creates an environment rampant with job insecurity. In a survey conducted by New America, fully three-quarters of the 1,600 respondents said it's easier to be successful with a degree than without one, in a finding that generally transcended the race of respondents. Yet 51 percent believe that plenty of well-paying jobs do not require going to college, despite solid evidence to the contrary (Fain, 2017). Education correlates unequivocally with the most significant social and financial results, for example, monetary achievement, wellbeing, family security, and social connections (Hout, 2012).

\section{Marriage}

\section{Marriage in Ghana}

A study was conducted by three students (2015) explored the extent to which marriage is associated with subjective well-being in Ghana. One of the findings from this study is that being married has a negative impact on well-being among Ghanaians, although the association is not statistically very strong (Addai, Opoku-Agyeman, \& Amanfu, 2015). This may be due to the prevailing cultural and socioeconomic contexts in poor countries, where well-being is predominantly predicted by economic factors. Another pertinent finding is that being married has a detrimental effect on happiness among females in Ghana. This finding suggests that the quality of marriage and traditional gender roles are essential in shaping wellbeing in Ghana - an important finding that demands further scrutiny (2015).

\section{Childbearing}

The Ashanti consider pregnancy to be a vulnerable time when risk increases that women may be affected by witchcraft and develop 'sunsumyare', a spiritual sickness that manifests itself as physical (Posega, 2014). Preparation for positive birth outcomes includes biomedical, ethnomedical and faith-based interventions (Farnes, Beckstrand, \& Callister, 2011). Motherhood is a primary role for Ghanaian women. The authors went on to explain that proven fertility is essential: "If you are not married, and you don't give birth, nobody cares. But if you are married and you don't give birth, the family of the man will not compromises with you" (Farnes, Beckstrand, \& Callister, 2010).

\section{Marriage in America}

The idea of marriage in the United States has changed many times over many centuries. Historian Nancy Cott argues that, since colonial times, Americans have viewed marriage as the bedrock of healthy families and communities, and vital to the functioning of democracy itself (Hull \& Ortyl, 2010). A study on early marriage conducted by Uecker and Stokes (2008) found that although much attention has been paid to the increasing age at first marriage in the United States, many Americans continue to marry at young ages. Many young people marry before their 23rd birthday. 
The implications of this review of literature are that there are similarities and differences in both countries when looking at family dynamics in particular. This research will continue to explore these through lived experiences of participants in the study.

\section{Research Question/s}

What are the cultural sharing patterns of family dynamics in Ghana versus the United States of America?

\section{Methodology}

This study was conducted using a qualitative design: an ethnographic approach. This approach explored the cultural sharing patterns in family dynamics in both Ghana and the USA. To answer the research question, 11-13 questions were asked during each focus group (see Appendix A). The responses from the focus groups in different countries were then compared and coded using Atlas Ti 8.0. Two focus groups were conducted in rural and urban cities in Ghana, while two focus groups were conducted in America. As the researcher, I was interested in studying the family dynamics in both countries in order to draw a comparison in the customs and beliefs of individuals and cultures. Various strategies were used to maintain the trustworthiness of the data such as following up with participants about their responses (member checking) and also noting their responses (rich thick descriptions).

\section{Sample and Procedure}

The focus group participants in Accra, Ghana included undergraduate students, faculty professors, and residents of Ghana. The bulk of the participants were students. Purposive sampling was used to gain participants and the inclusionary criteria was that each particpants had to be a member of that country (America or Ghana). In the rural part of Ghana, the participants were graduate students ranging from ages 22-30 years. The focus groups in America were conducted on a historically black college campus. All participants identified as African-American undergraduate students and ranged from the ages of 18-24. Participants were encouraged to share their experiences in daily life, education, occupation, role, and marriage within their families. The focus groups were conducted in private classrooms inside of academic buildings to ensure maximum privacy and confidentiality. Prior to conducting the focus group, permission was granted by the Clark Atlanta University's Institutional Review Board and each focus group participant was asked to complete a consent form that outlined the procedures and rules of the focus group. Involvement in the study was completely voluntary and the participants were notified that they could leave the group at any time. Each focus group was audio recorded, and the duration ranged from 30 minutes to 1 hour and 30 minutes. As an incentive for participating, participants in America received extra credit from their psychology professors. In Ghana, participants received gift bags that included a monetary gift as well as apparel.

\section{Data Analysis}

In order to effectively analyze the data collected in each focus group, Atlas Ti was used to formulate codes that did arise from the responses of the participants. These codes were then used to create themes that helped answer the 
overarching research questions. Validation techniques that were used in this study were member checking in which the participants were contacted after the focus group had ended to ensure that their responses had been recorded accurately. Saturation was reached after two focus groups. Triangulation was also used to validate this study by conducting focus groups in different areas in Ghana (rural and urban cities).

\section{Results}

Data was analyzed using Atlas Ti. Various codes were created based on the responses of the participants. Examples of codes that arose were anti-premarital childbearing, leisure, respected/non-respected occupations, matriarchy/patriarchy. These codes help formulate the themes and ideas for the study which are: Attitudes towards educational attainment, household dominance, daily family life, a ranking of occupations and attitudes toward marriage \& pre-marital childbearing. The themes are separated according to country, starting with data analyzed from American focus groups.

\section{Themes: America}

\section{Attitudes towards educational attainment}

The participants in the focus group were asked to describe how much value is put on receiving an education in their families. A comparison was drawn from the responses of both the focus groups in Ghana and the focus groups in America. The majority of the participants in America would be considered 1st-year college students meaning that prior to them attending college, no one in their immediate families had received post-secondary education. There are apparent differences in the responses from both countries. Below are some responses from participants from the focus group conducted in America.

Participant \#1: "My parents are very permissive, so if I want to go to college, I'll go. My mom cares, but if I was to drop out right now, she was would just say "it's up to you" My siblings would care more than my parents.

Participant \#2: “Mom doesn't see education as a priority because my brother only has an high school diploma. She does value education, though. My dad sees it as a priority."

Participant \#3: "Both of my parents push us to go to college (university or technical school). Education is valued because they didn't get it."

Participant \#4: Dad says, “it's your life. Do what you want to do as long as you are a good person”. Mom says, "you have to get an education or at lead get somewhere successful in life"

Participant \#1: "Education is valued because in the hood, it is seen as a way out, but everyone does not actually do it. It's kind of like a dream. I am the only person in my family that is in college." 
Participant \#2: "In my family, education is valued really high. It is a way out and get away from home. Besides my mom and uncle, I am the only person in my family that is in college and will complete college."

Participant \#3: “Pursuing an education is expected. If you go, you're praised. If you don't, you're isolated from the family. When I say education, I don't mean college. I mean learning more about what you want to do and learning everything about it so you can master it."

\section{Household dominance}

The participants in the focus group were asked to describe the dynamics in their households in terms of who holds the most power and makes the majority of the decisions. One participant shared a response that differed from the rest. Her sibling serves as head of the household, rather than a parent.

Participant \#1: "My sister is the person who gives money, plans things out, brings everyone together, and keeps the family in check. My dad doesn't do much. My mom makes the decision for him and he just goes with it."

Participant \#2: "My mom is really the head of everything. She pays for everything and sends money back to family members in Jamaica. My stepdad doesn't really do much."

Participant \#3: "In my dad's house, he runs everything. In my mom's house, it is a combination of me and her. I balance her out."

Participant \#4: "It's my mom. My dad is retired."

Participant \#5: "Men are the banks and women control everything. My family idolizes my grandmother like she is a God."

Participant \#6: "Dad is the go-to."

Participant \#7: "Mom takes care of the needs, while dad takes care of the wants."

\section{Daily family life}

Another theme that was identified during the analysis of the responses was daily family life. When asked to talk about daily life and activities, a large sum of the responses included being isolated from their families. A lot of the participants shared that while at home, they do not interact with their families and most of their time is spent in their rooms unless asked to do otherwise.

Participant \#1: "I take care of my nieces during the day. We don't eat a lot at all because we have been homeless a lot. We have learned to survive off of very little, so there is not much food in the house." 
Participant \#2: "Daily life at home is very unstable. All of my sisters are smokers, so when I go home there is a lot of smoking. It is a form of socializing."

Participant \#3: "I'm at home by myself when my dad or little brother are not there. Whatever groceries I find, that's what I eat. When I'm not at home, I go to work for 8 hours and then come home and do the same thing the next day."

Participant \#4: "My mom cooks breakfast and washes the dishes for us. Throughout the day, I'm just in my room. I don't realty have any interactions with my family. I only come out to take a shower, eat, or leave."

Participant \#5: "My time is split between two houses. At my dad's house, I really don't have any chores or duties. We don't really interact unless I need to ask him something. My mom makes me clean everything"

Participant \#6: “I take my brother to sports, I cook, and clean. I'm in my room most of the time so I don't have much interaction with anyone."

Participant \#7: "I'm usually the first person up in the morning around $10 \mathrm{am}$. I eat breakfast and wait for everyone to wake up. I drive mom around for errands. At night we watch the news as a family and family feud to conclude the day.

\section{Attitudes toward marriage \& pre-marital childbearing}

Marriage is not emphasized in the family lives of the participants. There was a consensus that marriage is much more so a legal agreement and a business than anything else. Having a child before getting married was also not seen as an issue among the majority of the participants. Emphasis is put on whether or not the family are fit and can support the child rather than them being married.

Participant \#1: "If you are living with a certain person for a certain period of time, you're technically married."

Participant \#2: "Marriage has changed so much. It is all about the logistics of the marriage license. It has no purpose, really."

Participant \#3: "Love and marriage is a business. Everyone has done it, it is like a tradition in a sense."

Participant \#4: "Marriage means nothing. You can get something back if the marriage fails. It is just a title. When it comes to pre-marital childbearing, my mom cares but my dad does not. My sister wouldn't approve at all."

Participant \#5: "Marriage is security, legal security. My parents don't care, but my brothers are strict." 
Participant \#6: "Marriage is a legal agreement. My mom would want me to wait until I am married."

Participant \#7: "Death partners. My parents are strict so they would want me to be married."

\section{Ranking of occupations}

Participants were asked to list occupations in which they found to be least respected and most respected in their cultures. Some participants, instead of stating specific jobs, they explained that not having the drive to work is least respected in their opinion.

\section{Least respected}

Below are examples of the occupations that were least respected:

Participant \#1: "Laying on your ass"

Participant \#2: "Selling your body"

Participant \#3: "Things you hate but keep doing."

Participant \#4: "New York City Housing Authority. They keep the neighborhood and apartment buildings clean."

Participant \#5: “Cops.”

Participant \#6: "Entry-level jobs and fast food."

Participant \#7: “Any entry-level jobs.”

\section{Respected}

Below are examples of the occupations that were respected:

Participant \#4: "The people that work in Manhattan offices."

Participant \#5: "Jobs that get you the flashiest things are most respected where I am from."

Participant \#6: "Lawyers, doctors, and scientists."

Participant \#7: "Manual labor jobs are most respected because you actually work for what you have." 


\section{Themes: Ghana}

\section{Attitudes towards educational attainment}

Participants described education as being a priority in their families. Obtaining higher degrees ensures that one will receive a career that pays well.

Participant \#1: "All four of my siblings graduated from college. All four of my siblings graduated from college"

Participant \#2: "Follow the example, so if your siblings or parents went to college, you should as well."

Participant \#3: "Education nowadays has become a last resort."

Participant \#4: "Very important if you want a good career."

Participant \#5: "Experience versus having life figure out."

\section{Household dominance}

Below are examples of the roles in each household, and who assumes these roles. The participants also provided information on what duties come with having these roles. ...

Participant \#1: "Mother is extremely quiet but make the decisions. "Your son wants this so get it for him." Dad pays bills, mom supports"

Participant \#2: "Dad, go to if you need someone to talk to."

Participant \#3: "Side with who you feel most comfortable with since my mother passed away."

Participant \#4: "Dad, head of the family. Calls meetings."

Participant \#5: "Mom, more strict"

\section{Daily family life}

Below are activities that occur on a day to day basis in the homes if the participants. These activities are for leisure or are mandated (chores). 
Participant \#1: "Playing games, soccer, and basketball. Mom traded at the markets. Dad is a lab technician, so he spends a lot of his time there"

Participant \#2: "Have to sweep, cook if needed if I am at home."

Participant \#3: "Texting with friends, watching television. Take care of little siblings when parents are not home."

Participant \#4: "Tours or stay at my shop. I also eat and hang out with friends"

Participant \#5: "Day starts at 4:30am, take a 2 hour walk, drink a ginger drink, take daughter to school. By 2:30pm, have to take a small nap. Between $4-10 \mathrm{pm}$ is the time to be productive. By $11 \mathrm{pm}$, I should be sleeping. If it goes beyond $11 \mathrm{pm}$, I cannot sleep until the next day."

\section{Attitudes toward marriage and childbearing}

Contrary to beliefs in an American home, marriage is emphasized in most Ghanaian families. Having a child before getting married is also frowned upon according to majority of the participants. Marriage is said to create a foundation for the child and sets the example for generations to come.

Participant \#1: No, child should come after marriage

Participant \#2: Yes, child can come before marriage

Participant \#3: No

Participant \#4: Indifferent

Participant \#5: "Yes, but my family is against it"

\section{Ranking of occupations}

Jobs were explicitly listed from Ghanaian participants. Higher-paying jobs are more respected than those that do not offer high salaries.

\section{Least respected}

Below are examples of the occupations that were respected:

- Parkers

- Cleaners

- Teachers (lower level)

- "Anyone who goes against the grain" 
- Drivers

\section{Respected}

Below are examples of the occupations that were respected:

- Lawyers

- Medical Doctors

- Engineers

- Business owners

- Bankers

- Independent business owners

- Fishermen ("boats are $\$ 10,000$ each, so if you have more than one, you are wealthy and respected")

- Athletes (futbol)

\section{Discussion/Comparison}

The purpose of this study is to explore and describe the family dynamics in Ghana, West Africa in comparison to those of African Americans in the United States of America. Analyzing these patterns is imperative when exploring the context of the historically black institution of higher learning, where African and American cultures intersect. When comparing attitudes towards education attainment, the responses from participants in America differed significantly from those in Ghana. In America, receiving a post-secondary education is optional rather than forced. Parents of many of the participants either dropped out of school, never attended school, or did not receive a postsecondary degree. The responses differed from the literature because Americans put such an emphasis on education because it leads to career attainment. These patterns differ from the responses received in Ghana because there is a strong emphasis on education. If anyone in the immediate family had attended college, it is imperative that the participant follows the example and does the same. Responses varied among the participants when asked to discuss the dominant figure in their home. Some shared that their fathers are the dominant figure, while others share that their mothers make the majority of the decision within the home. One individual who participated in the focus group in America admitted that neither one of her parents plays a dominant role in the home, her sister does. Daily family life was similar among the participants in both countries when it came to running errands and meals, however, isolation was a topic brought up during the focus group like occurred in America. Attitudes toward marriage and childbearing were more relaxed than in American families than they are in Ghana. Marriage in Ghana and scared and traditionally, having a child before marriage is frowned upon. Perceptions of marriage in America are overall negative because the consensus is that marriage is just an agreement or business of some sort and not as important. In turn, having a child before marriage does not go against the values of their families. As long as a person is able to provide for that child, marriage is not mandatory. Lastly, jobs that are respected in both countries are those in which more money is accumulated (doctors, lawyers, business owners, etc.) however, the least respected jobs differ in some ways.

In Ghana, jobs that require manual labor are not valued, but according to a participant in America, manual labor jobs are respected because they require hard work. Overall, there were a lot of interesting similarities and differences in family dynamics in both countries. Rich-thick descriptions were recorded while conducting the focus groups which 
allowed me to explore and analyze the experiences form each and every participant in detail. This study can be used as a guide to draw a comparison between other countries besides Ghana and the United States. Understanding the daily lives and contexts of individuals in Ghana and in the U.S. has not been conducted systematically to date, and such an exploration is expected to help build a bridge of understanding and respect between the related cultures in addition to using best practices that will benefit the cultures mutually. Analyzing these culture sharing patterns is especially important in the context of the historically black institution of higher learning, where African and American cultures intersect. Both groups, Africans in Africa and African Americans in the U.S., will benefit from this research because this will bridge gaps in knowledge, making us a citizen of the world.

\section{References}

Adu--Agyem, Joe \& Osei-Poku, Patrick. (2012). Quality education in Ghana: the way forward. International Journal of Innovative Research and Development, 1, 178-190.

Ampofo, A. (2001). "When Men Speak Women Listen": Gender socialisation and young adolescents' attitudes to sexual and reproductive issues. African Journal of Reproductive Health / La Revue Africaine De La Santé Reproductive, 5(3), 196-212. doi:10.2307/3583335

Blackstone, A. M. (2003). Gender roles and society. 355.

Boateng, E. A., Fage, J. D., Davies, O., \& Maier, D. J. (2019). Ghana. Retrieved from https://www.britannica.com/place/Ghana/Daily-life-and-social-customs\#ref260876

Bosak, J., Eagly, A., Diekman, A., \& Sczesny, S. (2018). Women and men of the past, present, and future: Evidence of Dynamic Gender Stereotypes in Ghana. Journal of Cross-Cultural Psychology, 49(1), 115-129.

https://doi.org/10.1177/0022022117738750

Farnes, C., Beckstrand, R. and Callister, L. (2011), Help-seeking behaviours in childbearing women in Ghana, West Africa. International Nursing Review, 58, 491-497. doi:10.1111/j.1466-7657.2011.00917.x

Hammond, D. (2016). Unequal opportunity: race and education. Retrieved December 9, 2019, from https://www.brookings.edu/articles/unequal-opportunity-race-and-education/

Horowitz, J. M., Parker, K., \& Stepler, R. (2019). Views of gender In The U.S. Retrieved from https://www.pewsocialtrends.org/2017/10/18/wide-partisan-gaps-in-u-s-over-how-far-the-country-has-come-ongender-equality/

Hout, M. (2012). Social and economic returns to college education in the United States. Annual Review of Sociology, 38, 379-400. Retrieved from http://www.jstor.org/stable/23254601 
Hull, K. E., Meier, A., \& Ortyl, T. (2010). The changing landscape of love and marriage. Contexts (Berkeley, Calif.), 9(2), 32-37. doi:10.1525/ctx.2010.9.2.32

Posega, J. M.(2014). A multi-sited examination of pregnancy, birth and women's perceptions of care in (Master's thesis). Retrieved from https://scholarcommons.sc.edu/etd/2869

Uecker, J. E., \& Stokes, C. E. (2008). Early marriage in the United States. Journal of Marriage and the Family, 70(4), 835-846. doi:10.1111/j.1741-3737.2008.00530.x

Wilkinson, Stephen \& Callister, Lynn (2010), Giving birth: The voices of Ghanaian women, Health Care for Women International, 31(3), 201-220, DOI: 10.1080/07399330903343858 